\title{
SOIL TEMPERATURE AND ELECTRIC POTENTIAL DURING DIURNAL AND SEASONAL FREEZE-THAW
}

\author{
S.I. Outcalt ${ }^{1}$, D.H. Gray ${ }^{2}$ and W.S. Benninghoff ${ }^{3}$ \\ Department of Geological Sciences', Department of Civil Engineering ${ }^{2}$ and Department of Biologr ${ }^{3}$, University of Michigan, \\ Ann Arbor, MI 48109 (U.S.A.)
}

(Received March 23, 1988; accepted in revised form July 25, 1988)

\section{ABSTRACT}

Combined measurements of soil temperature and electric potential in the upper $15 \mathrm{~cm}$ of a glacial sandy-loam soil were made during the winters of 1986-87 and 1987-88 at the University of Michigan Botanical Gardens using an electronic data acquisition system at frequencies varying from $10 \mathrm{~min}$ to daily (midnight). Most of the data was collected at hourly intervals.

Analysis of temperature-potential time series at two locations with probes at $(0,3,6,9)$ and $(0,5,10,15)$ $\mathrm{cm}$ depths indicated that the variation of electric potential relative to the potential of a $1.5 \mathrm{~m}$ ground spike could be interpreted as the response of an electrolytic concentration cell without transference formed by a probe and the ground spike. As the electrolyte concentration is much greater at the ground spike, and electric potential varies inversely with concentration, the potentials at the soil probes varied over the range of approximately 300-700 $\mathrm{mV}$ in a manner consistent with the behavior of a concentration cell.

The rapid and systematic pattern of potential variation during freeze-thaw events demonstrates that the effects of electrolyte concentration and dilution are products of evaporation-distillation, the melting of frost-purified ice, soil water advection to the freezing-evaporating region, concentrated electrolyte expulsion from the freezing region and the infiltration of rain and snow melt waters.

\section{INTRODUCTION}

In recent years measurements of electric potential variation across the freezing isotherm have been reported from permafrost regions (Parameswaran and Mackay, 1984; Parameswaran et al., 1985). These measurements demonstrated significant changes in electric potential near the freezing isotherm. The authors suggest as a working hypothesis that electric potential variation during soil freezethaw events may be interpreted as the product of soil electrolyte concentration variation resulting from phase change and advection. To test this hypothesis, instrumentation was developed to measure and record changes in soil temperature and electric potential near the soil surface at variable frequencies (daily, hourly or $10 \mathrm{~min}$ ).

Electric potential in soil in association with thermal potential has been recognized for over a century (Jumikis, 1984a). Civil engineers have given special attention to moisture transfer by thermo-osmosis in association with freezing (Jumikis, 1973), to the dewatering of fine-grained soils by applying electric current to generate electro-osmosis (Gray and Mitchel, 1967), and to the electrical thawing of frozen soils (Jumikis, 1984b). The study of passive generation of potential gradients in soils by thermal gradients has been confined largely to laboratory experiments (Hanley and Ramachandra Rao, 1980; Yarkin, 1986). Borovitskii (1976) measured electric potential across the freezing isotherm at the base of the active layer which did not exceed an absolute magnitude of $50 \mathrm{mV}$.

Although we believe that thermally induced concentration changes best explain the gross features of the measured electrical potentials, this interpretation does not preclude the presence of other coupling effects similar to those noted by Elrick et al. 
(1976). Several types of coupling effects could conceptually manifest themselves during freeze-thaw events in a soil-water-electrolyte system as a result of complex interactions between the flows of matter and energy. If indeed present, these effects would tend to modulate but not dominate concentration induced potentials associated with freezing and thawing.

As an example of a secondary coupling effect, freezing of soil water can give rise to a large soil water suction (negative pressure) with a strong advective flow of water into the freezing region. This advective flow in turn could produce an electrokinetic streaming potential. These electrokinetic potentials cannot account, however, for the magnitude and pattern of the observed electric potentials associated with frost-thaw events. Gray and Mitchel (1967) measured streaming potentials using reversible $\mathrm{Ag}-\mathrm{AgCl}$ electrodes on either side of homoionic clays and silty clays saturated with sodium chloride solutions varying in concentration from $10^{-3}$ to $10^{-4} \mathrm{~N}$. The measured streaming potentials varied from 1 to $60 \mathrm{mV} /$ atmosphere with potentials decreasing sharply as either the concentration of the pore water electrolyte or the exchange capacity of the clay soil increased.

Other types of induced potentials have also been cited from time to time in the technical literature, viz., diffusion potentials, phase boundary potentials, and freezing potentials. So called "freezing" potentials in the range of $0-25 \mathrm{mV}$ have been reported by Drost-Hansen (1967) in dilute aqueous solutions $\left(10^{-4}-10^{-3} \mathrm{~N} \mathrm{KCl}\right)$ between the advancing ice front (negatively charged) and unfrozen water (positively charged). This potential is alleged to arise as the result of the incorporation of ions into ice and the crystallographic rearrangement of water molecules as freezing occurs. It is interesting to note, however, that gentle stirring obliterated this potential. Stirring would also have the effect of eliminating concentration differences which suggests that the "freezing" potential is caused in part by ionic concentration differences near the ice interface.

In support of the working hypothesis the authors will demonstrate that the gross features of the electric potential fields generated by electrolyte concentration changes at the near surface probes are consistent with the behavior of concentration cells without transference (electrodes in isolated solutions) formed by the ground spike and individual near surface electrodes electrically connected through the soil. To make this point several time series are displayed in which electric potential has been converted to a linear surrogate measure of electrolyte concentration-activity and displayed with coincident thermal data.

\section{MEASUREMENT SYSTEM}

The data acquisition system is an Elexor $1000 \mathrm{H}$ driven by a Tandy Model 102 lap top computer. The Elexor has $16 \mathrm{~A} / \mathrm{D}$ channels which are divided between thermistor channels and electric potential channels. This permits the use of 8 soil probes. Each soil probe is constructed from a $5 \mathrm{~cm}$ length of copper tubing ( $8 \mathrm{~mm}$ OD) with three lead wires. Two of the leads are connected to an internal thermistor surrounded by high thermal conduction sealant and the third is connected to the copper tube for the electric potential measurements. The electric potential is read relative to a $1.5 \mathrm{~m}$ copper coated ground spike separated by a horizontal distance of $2 \mathrm{~m}$ from the near surface electrode arrays.

Yellow Springs Instruments \#44008 (30 K $\Omega$ @ $25^{\circ} \mathrm{C}$ ) thermistors are used for temperature measurement. Vendor-supplied data was used to calculate the parameters $(A, B, C)$ in eqn. (1) in which resistance $(R)$ is in ohms and the temperature $(T)$ is in degrees Kelvin:

$$
1 / T=A+B \log (R)+C[\log (R)]^{3}
$$

This standard curve fits all temperatures to within $\pm 0.007^{\circ} \mathrm{C}$ over the temperature range from -40 to $+50^{\circ} \mathrm{C}$ and showed a deviation of $+0.0011^{\circ} \mathrm{C}$ at the ice point. The probes were all placed in a plastic waste basket filled with melting ice slush to determine the correction resistance for each probe to bring it to the standard curve at the ice point. This calibration was carried out with the lead wires included using a calibration program within the data system. In the calibration and data acquisition programs the correction resistance for each probe is added to the probe resistance and then the temperature is calculated via the standard curve equation. 
Lastly, the slight deviation from the standard curve fit of $0.0011^{\circ} \mathrm{C}$ is subtracted from the calculated temperature. The calibration run was completed when all probes in the ice bath were reading $0.0000^{\circ} \mathrm{C}$ after passing through all the data reduction statements that were used in the acquisition program. The system has $1 \mathrm{mV}$ potential resolution in the range of $\pm 4.096 \mathrm{~V}$ and thus yields four significant figures, a sign and decimal point. It therefore appears that the temperatures are accurate to within $\pm 0.01^{\circ} \mathrm{C}$ over the entire environmental temperature range and were recorded to $0.01^{\circ} \mathrm{C}$ using four significant figures, a sign and decimal point. The data acquisition program and thermistor calibration program were written in the BASIC computer language furnished with the Tandy Laptop.

\section{FIELD INSTALLATION}

The site of the field study is a grass lawn, roughly mowed to about $3 \mathrm{~cm}$, enclosed by a fence at the University of Michigan Matthaei Botanical Gardens $1.5 \mathrm{~km}$ northeast of Ann Arbor, Michigan. The soil is a pebble-rich upland sandy loam of glacial origin with a plow zone approximately $10 \mathrm{~cm}$ deep. A mixture of loess and sandy loam is present in the disturbed plow zone. The probes were placed in two four-probe stacks, which are termed the west and east stacks. The probe depths at the west stack are $0,3,6,9 \mathrm{~cm}$ and $0,5,10,15 \mathrm{~cm}$ at the east stack. The surface probe in each stack was placed at the base of the grass mat and the deeper probes were centered on the indicated level. It is assumed that during frost-thaw events the probes may shift position and thus the spacing is not rigorous.

The probes are connected by cable to the data acquisition system which is housed in a small heated building on the experimental plot. The data system can write to either the lap top RAM (read/write memory) or directly to a cassette recorder. All the electric potential measurements are made relative to the copper coated ground spike. Thus, the ground spike and an individual probe form a concentration cell without transference deriving electromotive force from concentration variations within the same or at least similar electrolytes.

Reversible electrodes were not employed in these field experiments given uncertainty about the actual ionic composition of the soil pore water over time and the low probability that interface potentials at the electrodes would swamp or mask thermally induced concentration potentials between the reference ground spike and the near surface probe electrodes.

\section{THEORY}

The equation for the electric potential derived from a concentration cell without transference is given as eqn. (2) which is a slight modification of eqn. (89c) on page 554 of Prutton and Maron (1951):

$\epsilon=-2 \phi \log \left(C_{\mathrm{p}} / C_{\mathrm{s}}\right)$

Here the potential $(\epsilon)$ is derived from the electrolyte concentration-activity ratio $\left(C_{\mathrm{p}} / C_{\mathrm{s}}\right)$ at two electrodes (a soil probe, $p$, and the ground spike, $s$ ). It is significant that the $\left(C_{\mathrm{p}} / C_{\mathrm{s}}\right)$ ratio is dependent on the concentration and electrolytic activity of all the ionic species at each probe and a change in the ratio can be produced by both changes in species composition and concentration. To simplify further discussion it will be assumed that the ionic species composition at the ground spike and probes is similar and the ratio will be referred to as a concentration ratio. The symbol $(\phi)$ represents the gas constant and absolute temperature divided by the Faraday constant. Its value at the ice point is approximately $23.5 \mathrm{mV}$. If $\left(C_{\mathrm{s}}\right)$ is taken as the concentration at the ground spike and $\left(C_{\mathrm{p}}\right)$ as the concentration at a near surface probe, the field situation can be roughly evaluated. Probe potentials are typically in the realm of $300-700 \mathrm{mV}$ relative to the ground spike. Therefore, the soil electrolyte concentration must be much greater at the deep ground spike than at the probes. This finding is consistent with the assumption that the near surface layers are frequently flushed by relatively clear rain and snowmelt waters. It is also possible to consider the electric potential in eqn. (2) as a time dependent change in potential resulting from the present $(C)$ and previous $\left(C^{*}\right)$ electrolyte concentration at a single probe as shown in eqn. (3): 
$\Delta \epsilon=-2 \phi \log \left(C / C^{*}\right)$

An increase in concentration by a factor of 4 produced by the evaporation of electrolyte-rich water would produce a potential change of $-65.2 \mathrm{mV}$. In a similar manner, the expulsion of electrolyte from a freezing region or advection/infiltration of relatively clean water that produces a reduction in concentration by a factor of 4 would trigger a potential increase of $65.2 \mathrm{mV}$ at an individual probe.

The theory for a concentration cell with transference is quite similar. The present model was selected as it does not require hydraulic connection between the ground spike and the near surface probes. The rapid and selective response of the closely nested probes also suggests a non-transference model. The model circuit can be visualized as a potentiometer connected to two jars holding brine which are connected by a third conductor. The high concentration jar is the analog of the ground spike and the low concentration jar the probe analog. It is implicit that the electrolyte concentration measured by the deep ground spike is not strongly time dependent.

\section{SOIL FROST FUNDAMENTALS}

The freezing regime is characterized by the presence of ice and mobile soil pore water. When soil freezes the process usually begins at a temperature below the $0^{\circ} \mathrm{C}$ as ice crystals form in the soil pore water. The ice point is depressed below $0^{\circ} \mathrm{C}$ by the presence of impurities in the soil water. With further temperature depression more water is frozen until only strongly bonded immobilized soil water is present. As a frozen soil is warmed toward the $0^{\circ} \mathrm{C}$ isotherm the freezing region is again entered and the soil water volume fraction increases with temperature until thaw near $0^{\circ} \mathrm{C}$.

In the early stages of near surface soil freezing the soil water pressure at the ice-water interface is effectively a single valued function of temperature as indicated by eqn. (4), where $(\psi)$ is the soil-water pressure, $(\tau)$ is the absolute temperature at which ice first forms, $(T)$ is the absolute temperature of the soil-ice-water mix and $(g, L)$ are gravitational acceleration and the latent heat of fusion for ice (Taylor and Luthin, 1976):

$\psi=\{L /(T g)\}(\tau-T)$

In eqn. (4) the value of $[L /(T g)]$ is approximately $1.25 \times 10^{2}$ metres of water $/{ }^{\circ} \mathrm{K}$. Thus, when $(\tau-T)$ is in the realm of $-0.1^{\circ} \mathrm{C}$ the soil water tension (negative pressure) is in the realm of $12.5 \mathrm{~m}$ of water. This produces a strong flow of soil water into the freezing region as long as there is a sufficient water cross section to support the flow. As the temperature continues to drop, water advection to the freezing region cannot be maintained as the water conduits are both small and tortuous. In moist soils these strong pressure gradients can drive soil water into the freezing region from unfrozen regions both above and below the freezing region. This ice phase advection will affect the electrolyte concentration in a variable manner depending on the electrolyte concentration of the advected water.

The freezing regime is terminated when the hydraulic conductivity of the freezing soil becomes so low that water advection is no longer possible and a frozen regime is initiated in which hydraulic connection to warmer regions is extremely constrained or severed.

Before this event a significant transitional process may be initiated. As the ice volume increases to values greater than the initial porosity due to the ice/ water volume ratio or ice segregation with depressed temperature, electrolyte rich soil water is expelled from the coldest region into the pore water of the neighboring regions. The pore water electrolyte concentration increases in the near unfrozen/ freezing regions and decreases in the coldest region. The later thaw of soil-ice releases relatively pure ice-melt water decreasing the ion concentration.

Thus, there are two distinct types of soil water advection associated with soil freezing. During the early relatively warm stages of the freezing regime soil water moves toward the coldest region and during the final coldest stages of soil freezing ion rich water may be expelled from the coldest region. 
RELATIVE ELECTROLYTE CONCENTRATION

If eqn. (2) is rewritten with the concentration at a soil probe as the objective function the result is eqn. (5):

$C_{\mathrm{p}}=C_{\mathrm{s}} \operatorname{Exp}[-\epsilon /(2 \phi)]$

The data are more easily discussed in terms of linear relative soil electrolyte concentration than nonlinear electric potential. As the mid-range of electric potentials is in the realm of $500 \mathrm{mV}$ the ratio of the electrolyte concentration at the ground spike to the probe values is in the realm of $4.17 \times 10^{4}$. If this value is substituted for $\left(C_{\mathrm{s}}\right)$ in eqn. (5) a scale of relative concentrations at soil probes is produced which is normalized to unity at a potential of 500 $\mathrm{mV}$. This scale will be employed in the further analysis and is termed the $C$-index. The $C$-index is a surrogate of electrolyte concentration on a linear scale used to facilitate the discussion of the time series discussed in the next section.

\section{SOME OBSERVATIONAL DATA}

Three examples of different types of ground frost events will be presented. Although the analysis of the $C$-index time series is difficult in some cases, the electrolyte concentration is always extremely sensitive to phase change in the soil water system.

\section{Example 1. Three diurnal thaw events}

At the start of this record the ground was frozen at $5 \mathrm{~cm}$ and the $C$-index increased with depth. During the record the frost line descended to the $10 \mathrm{~cm}$ level. Some evidence of diurnal thermal fluctuation is evident at the $15 \mathrm{~cm}$ level (see Fig. 1 ).

The surface $C$-index tracks temperature. This is believed to result from the expulsion of ion rich water from the ice lattice during temperature depression and its re-introduction during warming due to water flow toward cold ice. At $5 \mathrm{~cm}$ there is a general increase in concentration which must be the product of upward water advection. A temperature tracking similar to the surface pattern modulates this trend. At $10 \mathrm{~cm}$ there is a sharp decrease
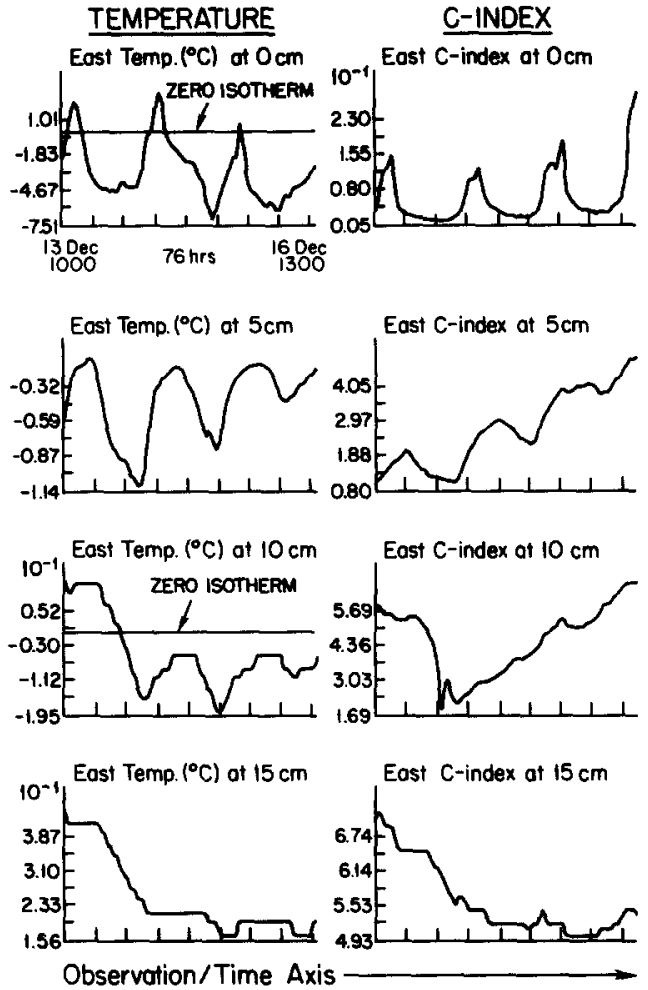

Fig. 1. Three diurnal thaw events. Saturday $12 / 13 / 8610: 00$ EST to Tuesday $12 / 16 / 86$ 13:00 EST. Hourly data interval ( 76 observations).

in concentration as ice forms followed by a gradual concentration increase to the record end. The concentration record at $15 \mathrm{~cm}$ appears to be controlled by early advection of relatively clean water from depth which is later countered or masked by the diurnal ion expulsion from the overlying frozen layers.

\section{Example 2. A diurnal frost event}

This event begins with high concentration at the surface and a decrease of two orders of magnitude between 3 and $6 \mathrm{~cm}$. The thermal record is typical of diurnal frost driven by thermal radiation cooling. The slight "bump" at all levels in the thermal record is diagnostic of warm water advection from depth (Outcalt, 1971). This advection brings ion rich water to the surface during the early part of the record (see Fig. 2).

Again, consistent with the hypothesis, nucleation 

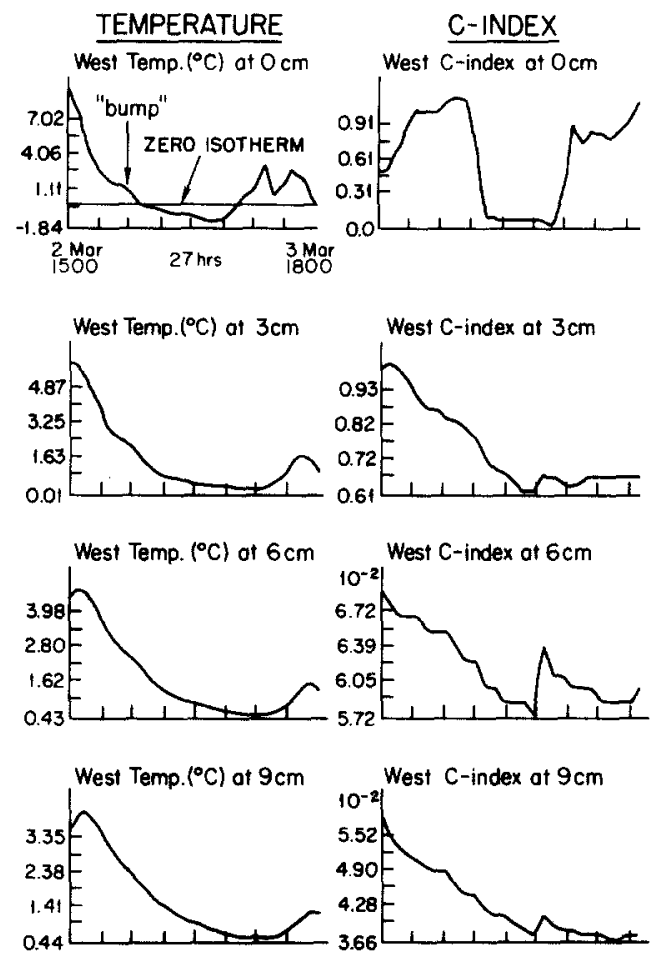

Observation/Time Axis

Fig. 2. A diurnal frost event. Monday 03/02/87 15:00 EST to Tuesday $03 / 03 / 8718: 00$ EST. Hourly data interval (28 observations ).

produces a rapid decrease of the surface $C$-index as ion rich water is expelled from the ice. The continued decline of the $C$-index at all sub surface levels is likely the result of the advection of water toward the surface from a deep source of relatively clean water. During the period near surface ice growth and evaporation act as a driving force for advection. The sharp increase in the $C$-index at all levels that accompanies surface melt may be the result of increased internal evaporation later attenuated by clean water advection from depth.

\section{Example 3. Ten days of frost advance}

At the start of this record all levels were unfrozen and there was a maximum of the $C$-index at $3 \mathrm{~cm}$. At surface nucleation a $C$-index climb is initiated which lasts until the end of the record. This may be the combined result of the expulsion of ions from scattered ice nucleation centers, the advection of ion
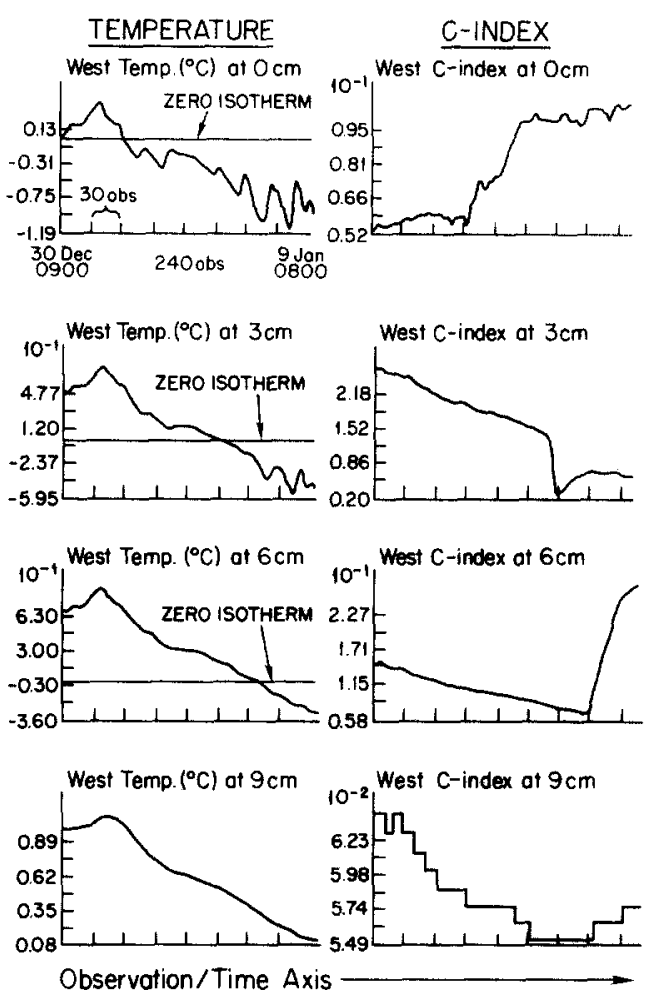

Fig. 3. Ten days of frost advance. Wednesday 12/30/87 09:00 EST to Saturday 01/09/88 08:00 EST. Hourly data interval ( 240 observations).

rich water from the $3 \mathrm{~cm}$ level to the freezing region and evaporation (see Fig. 3 ).

At $3 \mathrm{~cm}$ the $C$-index decline produced by upward clean water advection from depth becomes steeper and then increases after nucleation presumably as the product of ion exclusion. A similar $C$-index trend reversal occurs at $6 \mathrm{~cm}$ which probably results from ion expulsion. The $9 \mathrm{~cm}$ record appears to be dominated by clean water advection from depth toward the surface.

\section{CONCLUSIONS}

Soil electric potential fluctuations are strongly controlled by events which produce phase changes in the soil water and advection. These events in turn alter the ion concentration and thus indicate that the electrolytic cell without transference is a suitable physical model of the $C$-index time series. 
If the previous statement is true the combination of thermal and electric potential measurement should yield valuable insight into the geotechnical conditions in freezing soils.

In the data examples in the previous section there is the strong indication that the freezing regime is composed of two distinct sub-regimes. An initial ice nucleation regime in which the ice lattice is not contiguous enough to expel ion rich water and a colder regime which occurs as the frozen regime is approached when the $C$-index tracks the temperature fluctuations.

It therefore appears likely that the addition of soil potential electrodes to both field and laboratory instrumentation will yield valuable information concerning the state and mobility of the soil water.

\section{ACKNOWLEDGEMENTS}

Funds for the construction of the data acquisition system were provided by a development grant from the Office of the Vice-President for Research, Linda S. Wilson, of the University of Michigan. The system could not have been made operational without the extensive labors of Scott Baird, Electronics Technician, Department of Geological Sciences.

\section{REFERENCES}

Borovitskii, V.P. (1976). The development of inherent electric fields during the freezing of rocks in the active layer and their role in the migration of trace elements. J. Geochem. Exploration, (5): 65-70.

Drost-Hansen, W. (1967). Freezing potentials in dilute aqueous solutions. J. Colloid and Interface Sci., 25(2): 131-160.

Elrick, D.E., Smiles, D.E., Baumgartner, N. and Groenvelt, P.H. (1976), Coupling phenomena in saturated homoionic montmorillonite I. Experimental. Soil Science Soc. Amer. Proc., (40): 490-491.
Gray, D.H. and Mitchel, J.K. (1967). Fundamental aspects of electro-osmosis in soils. Proc. ASCE. J. Soil Mech. Found. Div., (93) (SM 6): 209-236.

Hanley, T.O'D. and Ramachandra Rao, S. (1981). Freezing potential studies in wet clays: I. Early results, and II. Specific systems. Cold Regions Science and Technology, 3(2): 163-175.

Jumikis, A.R. (1973). Thermo-osmotic soil moisture transfer upon freezing. In: Advanced Concepts and Techniques in the Study of Snow and Ice Resources. An Interdisciplinary Symp., Monterey, CA, Dec. 2-6, 1973. A United States Contribution to the International Hydrological Decade, National Academy of Sciences, Washington, DC, July, 1984, pp. 119-134.

Jumikis, A.R. (1984a). Soil Mechanics. R.E. Krieger Publ. Co., Malabar, Florida, 576 pp.

Jumikis, A.R. (1984b). Electrical thawing of frozen soils. Permafrost-Proc. 4th Int. Conf., Alaska, National Academy Press, Washington, D.C., pp. 333-337.

Outcalt, S.I. (1971). Field observations of soil temperature and water tension feedback effects on needle ice nights. Arch. Met. Geoph. Biokl. Ser. A., (20): 43-53.

Parameswaran, V.R. and Mackay, J.R. (1984). Field measurements of electrical freezing potentials in permafrost areas. Permafrost-Proc. 4th Int. Conf. Alaska, National Academy Press, Washington, D.C., pp. 962-967.

Parameswaran, V.R., Johnson, G.H. and Mackay, J. Ross (1985). Electrical potentials developed during thawing of frozen ground. Proc. 4th Int. Symp. on Ground Freezing/ Sapporo/5-7 Aug., 1985, pp. 9-15.

Prutton, C.F. and Maron, S.H. (1951). Fundamental Principles of Physical Chemistry. New York, MacMillan Co.

Taylor, G.S. and Luthin, J.N. (1976). Numeric results of coupled heat-mass flow during freezing and thawing. Proc. Second Conf. on Soil Water Problems in Cold Regions, Edmonton, Alberta, Sept. 1976, Division of Hydrology, American Geophysical Union, pp. 155-172.

Yarkin, I.G. (1986). Natural electrical potentials that arise when soils freeze. U.S. Army Corps of Eng., Cold Regions Research and Engineering Laboratory, Special Report 8612, 24 pp., Translation by T.O'D. Hanley of PhysicoChemical Processes in Freezing Soils and Methods of Controlling Them (in Russian), Moscow, Stroiizdat, pp. 59-81. 